\title{
Effect of Exchange Transfusions with Citrated Blood on Plasma Concentrations of Vitamin D Metabolites in Neonates
}

\author{
T. MARKESTAD, ${ }^{(26)}$ L. AKSNES, P. H. FINNE, AND D. AARSKOG \\ The Department of Pediatrics, University of Bergen, 5016 Bergen, Norway
}

\section{Summary}

The plasma concentrations of 25-hydroxyvitamin D (25OHD), 1,25-dihydroxyvitamin D (1,25-(OH) $)_{2}$ ), and 24,25-dihydroxyvitamin $\mathrm{D}\left(24,25-(\mathrm{OH})_{2} \mathrm{D}\right)$ were determined pre- and postexchange, and in donors' blood in 10 blood exchange transfusions with citrated blood for neonatal hyperbilirubinemia.

The postexchange concentrations of $25-\mathrm{OHD}$ and $24,25-$ $(\mathrm{OH})_{2} \mathrm{D}$ were intermediate between the levels before exchange and in donors' blood. Before therapy, the 1,25- $(\mathrm{OH})_{2} \mathrm{D}$ concentrations were higher in the infants' than in donors' blood, and the pre-exchange levels were re-established during the procedure.

The results suggest that postexchange concentrations of 25 OHD and $24,25-(\mathrm{OH})_{2} \mathrm{D}$ could be explained on the basis of redistribution of the metabolites between plasma and extravascular pools, whereas de novo synthesis was the most likely cause for the restoration of $1,25-(\mathrm{OH})_{2} \mathrm{D}$ levels.

\section{Abbreviations}

CPD, citrate-phosphate-dextrose

DBP or gc globulin, vitamin $D$ binding protein

1,25- $(\mathrm{OH})_{2} \mathrm{D}, 1,25$-dihydroxyvitamin $\mathrm{D}$

24,25-(OH $)_{2} \mathrm{D}, 24,25$-dihydroxyvitamin D

25-OHD, 25-hydroxyvitamin D

PTH, parathyroid hormone

The plasma concentrations of total and ionized $\mathrm{Ca}$ are high in cord blood, but decrease within 1-2 d of birth in healthy neonates $(4,11,20)$. The subsequent stabilization of $\mathrm{Ca}$ levels depends on a number of endocrine and non-endocrine factors, such as $\mathrm{Ca}$ and phosphate intakes, serum magnesium levels, and PTH and calcitonin secretions $(4,7,11,16,18)$.

The vitamin $D$ endocrine system is of prime importance for Ca homeostasis because it stimulates intestinal absorption and skeletal mobilisation of the ion (5). Its significance for immediate postnatal mineral metabolism, however, has not been defined (22).

In order to evaluate newborn infants' ability to produce 1,25 $(\mathrm{OH})_{2} \mathrm{D}$, which is the hormonal form of vitamin $\mathrm{D}$, we studied the effect of exchange transfusions with citrated blood on the plasma concentrations of vitamin D metabolites.

\section{MATERIALS AND METHODS}

Ten exchange blood transfusions were done for hyperbilirubinemia in seven newborn babies. Six of the infants had blood group incompatibilities, whereas one had jaundice of unknown etiology. Two were born prematurely (gestational ages, 30 and $35 \mathrm{wk}$, birth weights, 1300 and $1750 \mathrm{~g}$ ), the remainder were delivered at term and had appropriate birth weights (3000-4360 g). The pregnancies and deliveries had been uneventful. All had 1- and 5-min Apgar scores of eight or above, and none had neonatal disease other than the hyperbilirubinemia.

The exchange transfusions were performed at the median age of $38 \mathrm{~h}$ (range, $6-84 \mathrm{~h}$ ), and lasted for $1-1 \frac{1}{2} \mathrm{~h}$. The median volume of blood exchanged was $110 \mathrm{ml} / \mathrm{kg}$ body weight (range, $90-185 \mathrm{ml} / \mathrm{kg}$ ). No Ca was given during the procedure. CPD in a volume of $12 \mathrm{ml}$ per $100 \mathrm{ml}$ of blood, was used as anticoagulant and preservative for donors' blood.

Plasma was collected from the first and last aliquots aspirated from the babies and from the donors' blood. The concentrations of $25-\mathrm{OHD}, 1,25-(\mathrm{OH})_{2} \mathrm{D}$, and $24,25-(\mathrm{OH})_{2} \mathrm{D}$ were determined from $1.5 \mathrm{ml}$ of serum according to previously described methods $(1,2)$. All samples from one patient were analyzed in the same assay to minimize the effect of interassay variability. The intraand interassay coefficients of variation have been found to be 6.3 and $8.5 \%$, respectively, for 25-OHD; 9.7 and $12.1 \%$ for $1,25-$ $(\mathrm{OH})_{2} \mathrm{D}$; and 7.0 and $9.7 \%$ for $24,25-(\mathrm{OH})_{2} \mathrm{D}$.

Concentrations of vitamin D binding protein (gc globulin or DBP) were assessed by quantitative immunoelectrophoresis (13) using rabbit immunoglobulin to human gc globulin (DAKO immunoglobulins A/S, Denmark). Bilirubin and phosphate concentrations were determined by standard laboratory methods.

The data were expressed as medians with ranges. Differences were tested for statistical significance using the Wilcoxon test for paired data. Associations were calculated by linear regression analysis and expressed in terms of the correlation coefficient.

\section{RESULTS}

For $25-\mathrm{OHD}$ and $24,25-(\mathrm{OH})_{2} \mathrm{D}$, the postexchange concentrations were intermediate between the pre-exchange and donors' values, as were the bilirubin levels (Fig. 1). The postexchange values correlated with both the pre-exchange and the donors' levels, but more closely with the latter (25-OHD: $r=0.77, P<$ 0.05 , and $r=0.91, P<0.0005 ; 24,25-(\mathrm{OH})_{2} \mathrm{D}: r=0.69, P<$ 0.025 , and $r=0.94, P<0005)$.

The $1,25-(\mathrm{OH})_{2} \mathrm{D}$ levels before and after the exchange did not differ (medians, $50 \mathrm{pg} / \mathrm{ml}$ ), but both were markedly higher than that of donors' blood ( $24 \mathrm{pg} / \mathrm{ml}, P=0.001$, Fig. 1). The pre- and postexchange values were closely correlated $(r=0.95, P<$ 0.0005 , Fig. 2), but neither showed any association with the donor levels. The pattern of change was identical for the term and preterm infants, and for the first and second exchange. The pre-exchange values were, however, higher before the second than the first exchange in the three patients who had the procedure repeated.

The median concentrations of DBP did not change significantly between the groups of samples (donors' blood, 0.26 ; preexchange, 0.26; and postexchange, $0.25 \mathrm{~g} / 1$ ). Phosphate concentrations were higher in the donors' than in the infants' plasma 

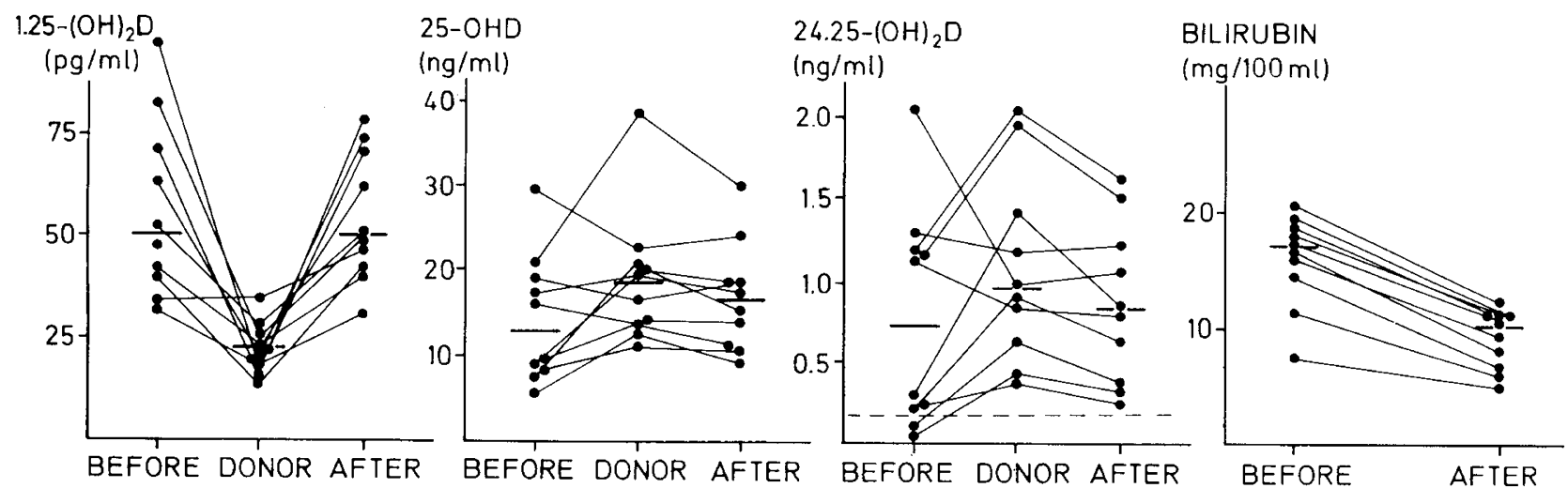

Fig. 1. Individual and median plasma concentrations of vitamin $D$ metabolites and bilirubin in neonates before and after exchange transfusions, and in donors' blood. The bilirubin levels of donors' blood were estimated to be close to 0 . The detection limit for $24,25-(\mathrm{OH})_{2} \mathrm{D}$ is plotted as a
horizontal broken line.

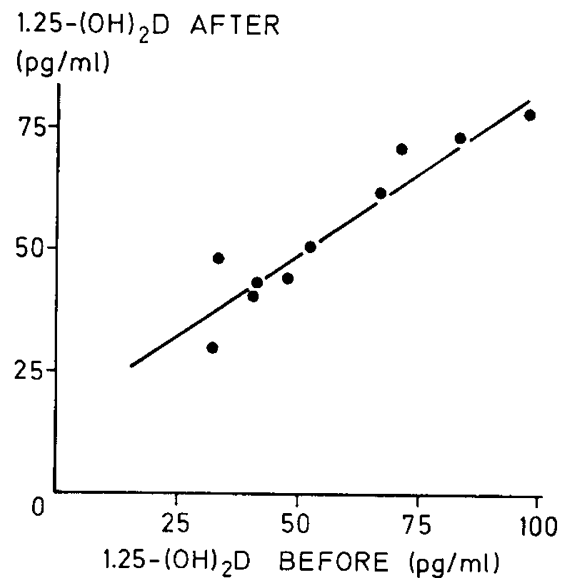

Fig. 2. Relationship between pre- and postexchange $1,25-(\mathrm{OH})_{2} \mathrm{D}$ levels, $r=0.95$ and $P<0.0005$.

before the exchange (medians, 9.0 versus $7.3 \mathrm{mg} / 100 \mathrm{ml}, P=$ $0.02)$.

\section{DISCUSSION}

Aside from hyperbilirubinemia, the infants were healthy and the plasma levels of all the vitamin D metabolites were within normal limits of age-matched infants before the exchange transfusions (14). During the course of a routine exchange transfusion, approximately $75-80 \%$ of the infants' blood volume is replaced with donors' blood (24). The vitamin D metabolites in the circulation will equilibrate rapidly with a smaller extravascular pool and slowly with a larger tissue compartment (17). The postexchange concentrations of $25-\mathrm{OHD}$ and $24,25-(\mathrm{OH})_{2} \mathrm{D}$, which were intermediate between the pre-exchange and donor values, can therefore be explained on the basis of simple redistribution of the metabolites between compartments, similar to what is known about bilirubin (23). The findings concur with the view that neither metabolite is actively regulated in response to changes in mineral homeostasis $(5,6)$.

The high $1,25-(\mathrm{OH})_{2} \mathrm{D}$ concentrations at the completion of the exchange transfusions, and the lack of association with the levels in the donors' blood, indicate that the plasma levels of this metabolite were actively re-established, and consequently that the vitamin D endocrine system is operating also in the early postnatal period. In agreement with this view, we and others have demonstrated a significant increase in $1,25-(\mathrm{OH})_{2} \mathrm{D}$ levels within 1-3 d of birth in term (21) and preterm (15) infants. In newborn rat pups, however, no $1,25-(\mathrm{OH})_{2} \mathrm{D}$ appears to be produced in the first week of life, even in response to hypocal- cemia (25). Similarly, Seino et al. (19) failed to demonstrate any increase in $1,25-(\mathrm{OH})_{2} \mathrm{D}$ levels in term infants during the first 5 $\mathrm{d}$ of life, and premature babies studied by Glorieux et al. (10) achieved a rise in $1,25-(\mathrm{OH})_{2} \mathrm{D}$ levels only if pharmacologic doses of vitamin $\mathrm{D}$ had been given since birth (10).

Exchange transfusions with citrated blood precipitates a considerable decrease in plasma ionized $\mathrm{Ca}(9)$, and an immediate compensatory rise in PTH levels $(7,16)$. PTH, and possibly hypocalcemia per se, stimulates $1,25-(\mathrm{OH})_{2} \mathrm{D}$ synthesis, but hours are believed to be required to observe an increase in plasma levels $(3,8,12)$. The present study does not allow any conclusion as to whether the restoration of the $1,25-(\mathrm{OH})_{2} \mathrm{D}$ concentrations reflected only the infants' basal production or also an increased synthesis in response to the exchange transfusion. Either way, the results suggest that healthy newborn babies have a high potential for rapid $1,25-(\mathrm{OH})_{2} \mathrm{D}$ synthesis in the immediate postnatal period.

\section{REFERENCES AND NOTES}

1. Aksnes, L.: Quantitation of the main metabolites of vitamin $D$ in a single serum sample. I. Extraction, separation and purification of metabolites. Clin. Chim. Acta, 104: 133 (1980).

2. Aksnes, L.: Quantitation of the main metabolites of vitamin D in a single serum sample. II. Determination by UV-absorption and competitive protein binding assays. Clin. Chim. Acta, 104: 147 (1980).

3. Aksnes, L. and Aarskog, D.: Effect of parathyroid hormone on 1,25-dihydroxyvitamin D formation in type I pseudohypoparathyroidism. J. Clin. Endocrinol. Metab., 51: 1223 (1980).

4. David, L. and Anast, C. S.: Calcium metabolism in newborn infants: The interrelationship of parathyroid function and calcium, magnesium and phosphorus metabolism in normal, "sick", and hypocalcemic newborns. J. Clin. Invest., 54: 287 (1974).

5. DeLuca, H. F.: Vitamin D. Metabolism and function. Monographs on Endocrinology (Springer-Verlag, Berlin-New York, 1979).

6. DeLuca, H. F.: Recent advances in the metabolism of vitamin D. Annu. Rev. Physiol., 43: 199 (1981).

7. Dincsoy, M. Y., Tsang, R. C., Laskarzewski, P., Chen, M.-H., Chen, I.-W., Lo, D., and Donovan, E. F.: The role of postnatal age and magnesium on parathyroid hormone responses during "exchange" blood transfusions in the newborn period. J. Pediatr., 100: 277 (1982).

8. Eisman, J. A., Prince, R. L., Wark, J. D., and Moseley, J. M.: Modulation of plasma 1,25-dihydroxyvitamin $\mathrm{D}$ in man by stimulation and suppression tests. Lancet, ii: 931, (1979).

9. Friedman, Z., Hanley, W. B., and Raddle, I. C.: Ionized calcium in exchange transfusion with THAM-buffered ACD blood. Can. Med. Assoc. J., 107: 742 (1972).

10. Glorieux, F. H., Salle, B. L., Delvin, E. E., and David, L.: Vitamin D metabolism in preterm infants: Serum calcitriol values during the first five days of life. J. Pediatr., 99: 640 (1981).

11. Hillman, L. S., Rojanasathit, S., Slatopolsky, E., and Haddad, J. G.: Serial measurements of serum calcium, magnesium, parathyroid hormone, calcitonin, and 25-hydroxy-vitamin $\mathrm{D}$ in premature and term infants during the first week of life. Pediatr. Res., 11: 739 (1977).

12. Lund, B., Sørensen, O. H., Lund, B., Bishop, J. E., and Norman, A. W Stimulation of 1,25-dihydroxyvitamin $D$ production by parathyroid hormone and hypocalcemia in man. J. Clin. Endocrinol. Metab., 50:480 (1980).

13. Laurell, C.-B.: Electroimmuno assay. Scand. J. Clin. Lab. Invest., 29 (suppl. 
124): 21 (1972).

14. Markestad, T.: Plasma concentrations of 1.25-dihydroxyvitamin D, 24,25dihydroxyvitamin $D$, and 25,26-dihydroxyvitamin $D$ in the first year of life. J Clin. Endocrinol. Metab., 57: 755 (1983).

15. Markestad. T., Aksnes, L., Finne, P. H., and Aarskog, D.: Plasma concentrations of vitamin D metabolites in premature infants. Pediatr. Res., (in press).

16. Milner, R. D. G. and Woodhead. J. S.: Parathyroid hormone secretion during exchange transfusion. Arch. Dis. Child., 50: 298 (1975).

17. Omdahl, J. L. Allen, R. C., and Eaton, R. P.: Computer modeling of vitamin $\mathrm{D}$ metabolism. In: Anthony W. Norman et al., eds.: Vitamin D, basic research and its clinical application. pp. 515-21 (Walter de Gruyter, BerlinNew York, 1979).

18. Schedewie, H. K., Odell, W. D., Fisher, D. A., Krutzik, S. R., Dodge, M., Cousins, L., and Fiser, W. P.: Parathormone and perinatal calcium homeostasis. Pediatr. Res., 13: 1 (1979).

19. Seino, Y., Ishida, M., Yamaoka, K., Ishii, T., Hiejima, T., Ikehara, C., Tanaka, Y., Matsuda, S., Shimotsuji, T., Yabuuchi, H., Morimoto, S., and Onishi, T.: Serum calcium regulating hormones in the perinatal period. Calcif. Tissue Int., 34: 131 (1982).

20. Snodgrass, G. J. A. I., Stimmler, L., Went, J., Abrams, M. E., and Will, E. J.: Interrelations of plasma calcium in organic phosphate, magnesium, and protein over the first week of life. Arch. Dis. Child., 48: 279 (1973).
21. Steichen, J. J., Tsang, R. C., Gratton, T. L., Hamstra, A., and DeLuca, H. F.: Vitamin D homeostasis in the perinatal period. N. Engl. J. Med., 302: 315 (1980).

22. Tsang, R. C. and Erenberg, A. P.: Calcium homeostasis in the newborn-the calciotropic hormones: parathyroid hormone, calcitonin, and vitamin D. In: Mors, A. J., ed.: Pediatric update. pp. 193-241 (Blackwell Scientific Publications, Oxford-Boston, 1980).

23. Valaes, T.: Bilirubin distribution and dynamics of bilirubin removal by exchange transfusion. Acta Paediatr. Scand., 52 (suppl. 149): 604 (1963).

24. Valaes, T. and Hyte, M.: Effect of exchange transfusion on bilirubin binding. Pediatrics, 59:881 (1977).

25. Weisman, Y., Sapir, R., Haell, A., and Edelstein, S.: Maternal-perinatal interrelationships of vitamin D metabolism in rats. Biochim. Biophys. Acta, 428: 388 (1976).

26. Requests for reprints should be addressed to: Dr. T. Markestad, Department of Pediatrics, N-5016 Haukeland sykehus, Bergen, Norway.

27. The authors thank Dr. J. L. Omdahl, The University of New Mexico School of Medicine, Albuquerque, New Mexico, for helpful advice.

28. This research was supported by The Norwegian Research Council for Science and the Humanities, and the Nestle Nutrition Research Grant Programme.

29. Received for publication March 15, 1983.

30. Accepted for publication July 14, 1983.

\title{
Antibody to Pseudomonas Aeruginosa Mucoid Exopolysaccharide and to Sodium Alginate in Cystic Fibrosis Serum
}

\author{
DAVID P. SPEERT, (33) DANIEL LAWTON, AND LUCY M. MUTHARIA \\ Division of Infectious Diseases, [D.P.S., D.L.J British Columbia Children's Hospital and the Departments of \\ Pediatrics [D.P.S.J and Microbiology [D.P.S. and L.M.M.], University of British Columbia, \\ Vancouver, British Columbia, Canada
}

\begin{abstract}
Summary
Antibodies in cystic fibrosis (CF) sera to Pseudomonas aeruginosa mucoid exopolysaccharide and to sodium alginate (a polysaccharide from seaweed chemically similar to mucoid exopolysaccharide) were measured in sera of CF patients to determine if the exopolysaccharide is immunogenic. An enzyme-linked immunosorbent assay was used to test sera from $26 \mathrm{CF}$ patients (18 colonized with pseudomonas and eight non-colonized) and 26 healthy controls. CF patients colonized with pseudomonas had more antibody to mucoid exopolysaccharide $(P=0.0008)$ and to sodium alginate $(P=0.0008)$ than did non-colonized $C F$ patients. Virtually none was found in healthy controls. Duration of colonization was correlated with the level of antibody to sodium alginate $(P=0.003)$ but not with antibody to mucoid exopolysaccharide. Mucoid exopolysaccharide is immunogenic in patients with $\mathrm{CF}$.
\end{abstract}

\section{Abbreviations}

CF, cystic fibrosis

ELISA, enzyme-linked immunosorbent assay

MEP, mucoid exopolysaccharide

OD, optical density

PA, Pseudomonas aeruginosa

PBS, phosphate-buffered saline

PBS/FBS, phosphate-buffered saline with $1 \%$ fetal bovine serum
In most older patients with $\mathrm{CF}$ oropharyngeal colonization and pulmonary infection with mucoid PA ultimately occurs $(5$, $14,26,30)$ and may be associated with an adverse prognosis (14). Mucoid PA elaborates a copious amount of an exopolysaccharide (closely resembling alginic acid from seaweed) that is responsible for its growth in the mucoid form (9). Colonization with mucoid PA once established usually persists, but the pathogenic role for PA and its mucoid exopolysaccharide (MEP) is poorly understood. We used a sensitive enzyme-linked immunosorbent assay to measure antibody to MEP and to sodium alginate in CF sera in order to determine if MEP is immunogenic. Antibodies to both MEP and to sodium alginate were found in CF sera; the level of antibody to sodium alginate was correlated with duration of colonization with mucoid PA.

\section{MATERIALS AND METHODS}

Subjects. Sera from 26 patients with CF and 26 healthy adults (obtained from the Vancouver Red Cross) were tested for antibody to MEP and to sodium alginate. After informed consent was obtained, venous blood was drawn from all subjects, and allowed to clot at room temperature for $45 \mathrm{~min}$. The serum was frozen at $-70^{\circ} \mathrm{C}$ until used. Eighteen $\mathrm{CF}$ subjects (age, 3-24 yr; mean, $12.5 \mathrm{yr}$ ) were colonized with PA, but eight $\mathrm{CF}$ subjects (age 6 mo to $26 \mathrm{yr}$; mean, $7.5 \mathrm{yr}$ ) had always been free of PA in throat and sputum cultures. Disease severity was assessed using 